\title{
Managing asthma patients: which outcomes matter?
}

\author{
A.P. Greening*, D. Stempel ${ }^{\#, \text {, E.D. Bateman }}{ }^{+}$and J.C. Virchow ${ }^{\S}$
}

ABSTRACT: Within the respiratory specialist community, there is growing recognition that classification of asthma based on severity of symptoms alone may not accurately reflect the clinical status of a patient. It follows, therefore, that treatment decisions based on this classification can lead to suboptimal management of asthma.

The concept of assessing patients by their level of asthma control is gaining wide acceptance and is a major component of the new 2006 Global Initiative for Asthma guidelines. Questions remain, however, on how best to achieve and maintain asthma control.

Randomised controlled trials have shown that very good asthma control is achievable in the majority of patients. There is a need for a tool to accurately assess a patient's level of control in the clinical setting if such results are to be replicated in practice.

A symposium at the European Respiratory Society Annual Congress in 2006 discussed the important issues that are currently facing asthma clinicians. The current article summarises the main points arising from that symposium.

KEYWORDS: Asthma, asthma control test, classification, control, combination therapy, management

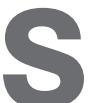

ignificant advances have been made in the treatment of asthma over the past 10 yrs. Highly efficacious therapies are available, which have significantly contributed to the global decline in asthma mortality observed since the mid-1990s [1-4]. Asthma morbidity, however, remains a significant problem, and the global burden is set to increase as a result of the projected rise in the prevalence of asthma. Recent estimates suggest that there will be an additional 100 million people with asthma by 2025 [5].

There is currently no cure for asthma. Therefore, the priority in terms of treatment is to reduce morbidity and mortality. The most crucial issue facing asthma clinicians today is how best to manage patients to reduce the substantial burden associated with this disease. Key factors include optimal assessment of patients, effectiveness of therapies and which treatment strategies provide the greatest benefits.

\section{CLASSIFICATION OF ASTHMA: SEVERITY VERSUS CONTROL}

When making treatment decisions, it is important to consider which outcomes are most relevant to the patient. Of key significance are potential improvements in the patient's health-related quality of life and the reduction in the societal burden of asthma.

Historically, asthma has been categorised according to the severity of symptoms: mild intermittent, mild persistent, moderate persistent and severe persistent. This classification quantifies departure from the normal state and suggests a consistency over time. In reality, however, symptoms and the severity of these symptoms may vary frequently.

The Global Initiative for Asthma (GINA) now recommends a classification according to asthma control: controlled, partly controlled or uncontrolled [6]. This system takes into account the underlying disease severity, the responsiveness to treatment and the recognition that symptoms and limitations may vary over time. Control is defined as achieving all of the following goals of therapy: 1$)$ no $\left(\leqslant 2 \cdot\right.$ week $\left.^{-1}\right)$ daytime symptoms; 2) no limitations on daytime activities, including exercise; 3) no nocturnal symptoms or awakening because of asthma; 4) no $\left(\leqslant 2 \cdot\right.$ week $\left.^{-1}\right)$ need for reliever medication; 5) normal or near-normal lung function; and 6) no exacerbations.

During the symposium at the European Respiratory Society Annual Congress in 2006, D. Stempel, from the University of Washington School of Medicine, Seattle, WA, USA, explained that, to have a better understanding of a patient's disease, physicians should carefully consider how they enquire about asthma symptoms. How a question is phrased can substantially influence the clinical usefulness of a patient's reply. A physician may ask his or her patient "Are you breathless upon exercise?", but in
AFFILIATIONS

${ }^{*}$ Respiratory Unit, Western General Hospital, Lothian University Hospitals Division and University of Edinburgh Edinburgh, UK

\#Infomed Northwest, Bellevue, "University of Washington, Seattle, WA, USA

+Division of Pulmonology, Dept of Medicine, University of Cape Town, Cape Town, South Africa. ${ }^{\S}$ Dept of Pneumology, University Medical Clinic, University of Rostock, Germany.

CORRESPONDENCE

A.P. Greening

Respiratory Unit

Western General Hospital Lothian University Hospitals Division and University of Edinburgh

Crewe Road South

Edinburgh EH4 2XU UK

Fax: 441315371038 E-mail: a.greening@ed.ac.uk

\section{SUPPORT STATEMENT}

The symposium discussed in the present article was sponsored by GlaxoSmithKline (Uxbridge, UK)

STATEMENT OF INTEREST

A statement of interest for all authors can be found in the

Acknowledgements section. 
addition one needs to ask "Do you exercise?". This can help to determine whether the patient was modifying his or her behaviour in response to symptoms.

Physicians also need to assess symptoms longitudinally. A study by FUHLBRIGGE et al. [7] found that there was discordance in the classification of asthma patients as mild intermittent, mild persistent or moderate/severe persistent, depending on whether the clinician assessed short- or long-term symptoms, the functional impact of symptoms, or a combination of shortand long-term symptoms (fig. 1). What emerges is the principle that the more detailed the history, the more likely it is that a patient will be assessed accurately.

There are clear risks from underestimating the impact of asthma. Underdiagnosis and undertreatment increase shortterm risks, such as loss of productivity and greater healthcare resource utilisation. In addition, there is also a potential for increased long-term risk.

The severity of asthma reflects stable, intrinsic criteria, such as genetics and the duration of disease. However, evaluating the level of asthma control could be a more comprehensive assessment of a patient's disease state than the evaluation of symptoms alone, because it takes into account the fact that asthma is a dynamic disease where control may change and can be modified by extrinsic triggers and therapy. Control is best represented as a threshold at which a satisfactory state is achieved; classifying and treating according to the level of

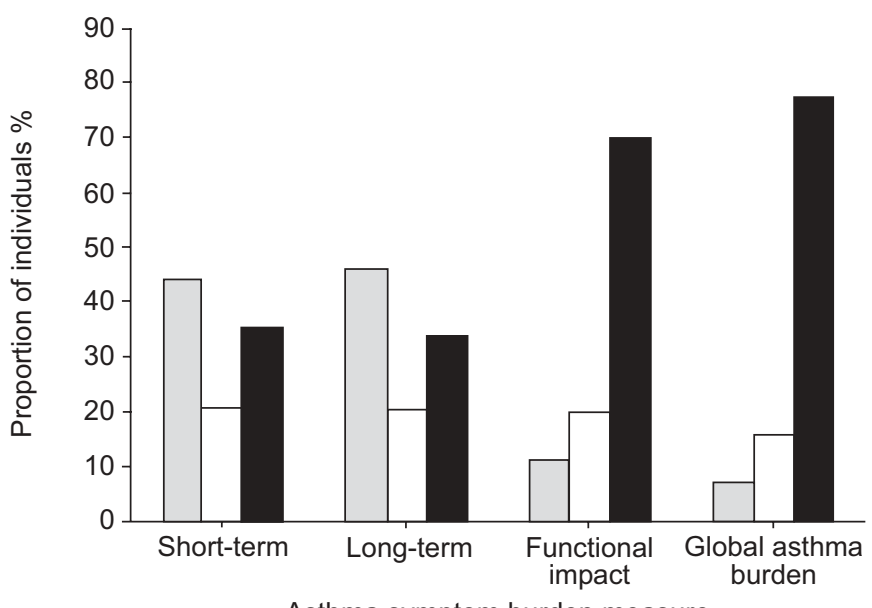

Asthma symptom burden measure

FIGURE 1. The proportion of individuals classified as having mild intermittent $(\square)$, mild persistent $(\square)$ or moderate/severe persistent $(\square)$ disease is shown, stratified by assessing different measures of asthma burden (short-term symptom burden, long-term symptom burden, functional impact and global symptom burden). Short-term symptom burden was categorised on the basis of reported daily and nocturnal symptoms over the previous 4 weeks. Long-term symptoms included the recall of average weekly symptoms and the frequency of asthma exacerbations over a 12-month period. Functional impact comprised three components: physical, social and nocturnal impact, each graded on a four-point Likert scale from 0 (none) to 3 (a lot). Global symptom burden combines both shortand long-term symptom burdens. The criteria for categorising asthma severity were based on the National Asthma Education and Prevention Program (NAEPP) Expert Panel II recommendation, with moderate and severe persistent asthma being combined. Reproduced and modified from [7] with permission of the publisher. control is more useful than according to severity of disease because, while severity reflects the status of disease, control gives an indication of the adequacy of treatment [8].

\section{ARE PATIENTS WITH MILD ASTHMA AT RISK?}

One of the barriers to achieving optimal asthma control in patients with mild asthma is that such patients are often undertreated. This results from the perception that they are at a lower risk of death or long-term complications than patients with more severe disease. Patients with mild disease use significant healthcare resources and have a reduced quality of life compared with the healthy population [9-11]. The risk of death may also be underestimated: a study in children with asthma found that rates of death were similar among patients considered mild, moderate and severe [12]. However, as spirometry was not available in most cases, it is unclear whether those patients classed as having mild asthma were truly either mild or poor perceivers of health status, or whether the assessments of severity prior to the deaths were inaccurate.

Studies indicate that airway inflammation and the associated structural changes are common to all levels of asthma severity, including patients in apparent clinical remission (fig. 2) [13]. This is particularly significant because injury and chronic airway inflammation initiate a repair process that results in structural remodelling of the airways [14, 15].

When asked whether he thought remodelling was sufficiently important to warrant its prevention by inhaled corticosteroids, D. Stempel highlighted the fact that there is no agreement on what constitutes remodelling and what the most appropriate markers of remodelling are. Greater consensus on these issues must be reached before the impact of inhaled corticosteroid therapy on remodelling can be assessed. J.C. Virchow, from the Dept of Pneumology, University Medical Clinic, University of Rostock, Germany, pointed out that many clinical trials focus on single end-points (such as reversibility), which allow only limited interpretation. Most chronic inflammatory diseases, including asthma, are associated with scarring and injury-andrepair processes. In J.C. Virchow's opinion, remodelling of the airways should be prevented by early inhaled corticosteroid therapy, although he conceded that there is currently no reliable marker of remodelling.

Treatment with anti-inflammatory therapy results in improvements in multiple markers of inflammation, even in patients in apparent clinical remission (fig. 3) [16, 17]. Therefore, basing therapy on single parameters could yield differing perceptions of successful treatment. Ideally, treatment decisions should be based on the results from multiple assessments.

D. Stempel highlighted the clear risks involved in making treatment decisions based on a patient's asthma symptoms alone, using the following case report as an example. A 24-yrold female presented with exercise-induced asthma that was not responsive to salbutamol. The patient had a history of asthma from the age of 5 yrs and had experienced two to three acute episodes of asthma per year, each associated with respiratory infections. These acute episodes had been treated successfully with oral corticosteroids and salbutamol, and between these acute episodes the patient had reported minimal nocturnal and daytime symptoms. On the basis of this 

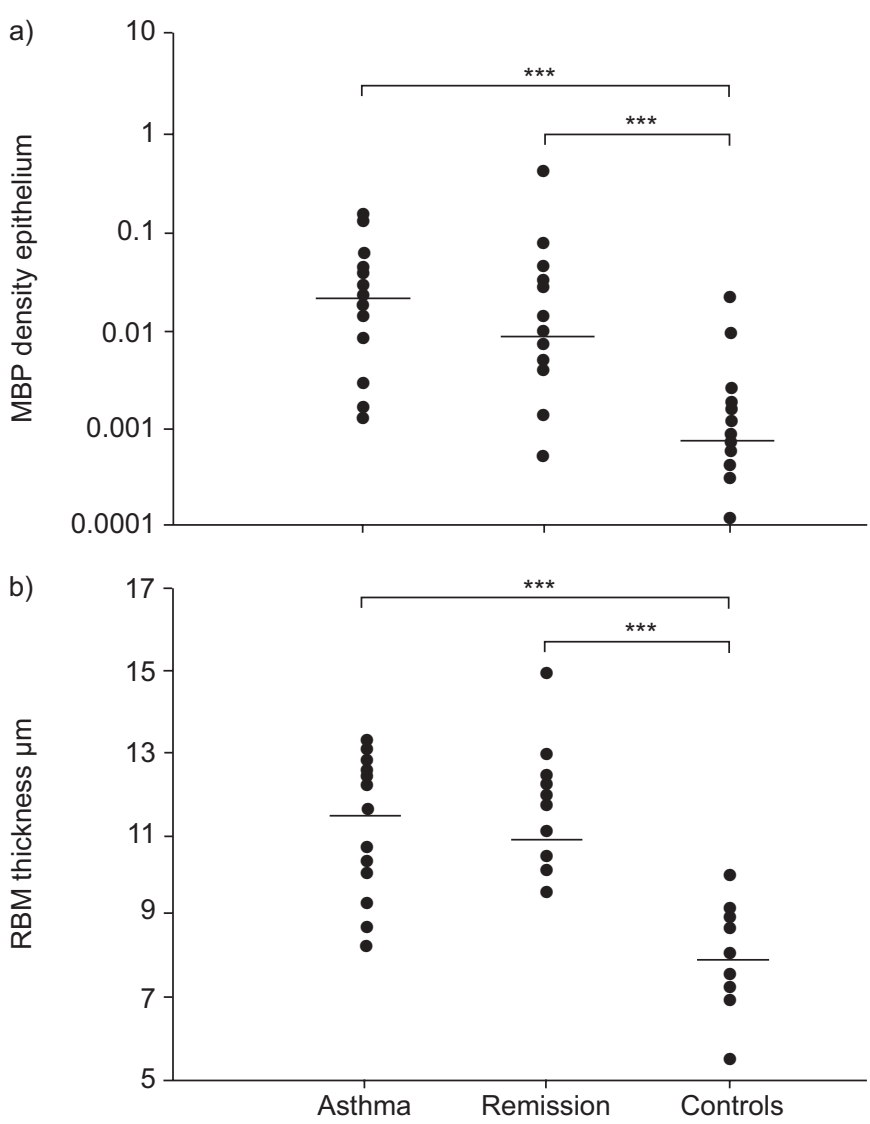

FIGURE 2. Comparison of biopsy specimens from asthmatic patients, patients in clinical remission from atopic asthma and healthy controls. a) The ratio of area of major basic protein (MBP) staining to total area of epithelium, reflecting a marker of active inflammation. b) The thickness of the reticular basement membrane (RBM). The number of subjects in each group was as follows. Asthmatics: a) $n=19, b$ ) $n=20$; remission: a) $n=18$, b) $n=17$; controls: a) $n=17$, b) $n=16$. $\bullet$ : represents one patient; —_: median values. ${ }^{* *}: p<0.001$. Reproduced and modified from [13] with permission of the publisher.

information, the patient could be classified as having mild persistent asthma.

Spirometry revealed a forced expiratory volume in one second (FEV1) of $91 \%$ predicted, a forced vital capacity (FVC) of $108 \%$ pred and FEV1/FVC of $84 \%$. The patient was treated with salmeterol/fluticasone propionate (Seretide ${ }^{\circledR} /$ Advair $^{\circledR}$, 50/ $100 \mu \mathrm{g}$ b.i.d.; both GlaxoSmithKline, Uxbridge, UK). The subject subsequently reported an improvement on exercise and suffered no exacerbations requiring oral corticosteroids during respiratory infections in winter. Interestingly, after treatment, the patient also reported that she no longer awoke with a morning cough, which she had previously perceived as normal.

The 2006 GINA report represents a clear shift in the way in which asthma is assessed and managed [6]. It is now recognised that assessing patients according to control acknowledges and takes into account the dynamic nature of the disease. Complete assessment of asthma control better reflects the day-to-day variability of the disease and requires careful assessment of multiple factors including, but not limited to, symptoms and airflow obstruction.
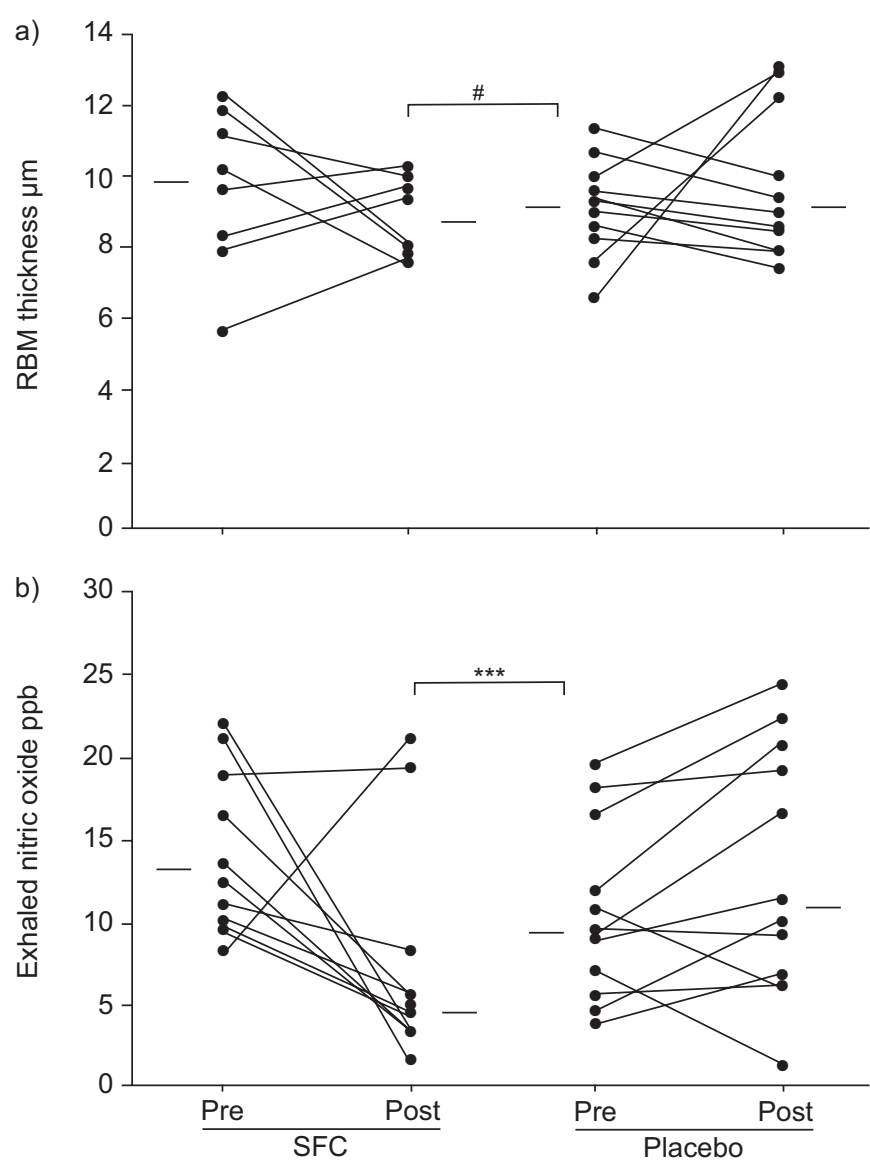

FIGURE 3. Response to treatment with salmeterol/fluticasone propionate (SFC) in surrogate markers of inflammation in asthma patients who had had a complete absence of symptoms for at least 12 months. a) Reticular basement membrane (RBM) thickness and b) exhaled nitric oxide levels show data pre- and post-treatment for 3 months with SFC 50/250 mg b.i.d. or placebo (normal nitric oxide levels: 7-8 ppb [17]). Each line represents one patient. ——: median values. \#: $p=0.05$. ${ }^{* *}: p<0.001$. The $p$-values are for between-treatment differences Reproduced and modified from [16] with permission of the publisher.

\section{COMBINATION THERAPY: CHANGING PERCEPTIONS}

Inhaled corticosteroids are the most effective treatment for the control of airway inflammation [6] and, as such, remain the cornerstone of asthma therapy. In the late 1980s and early 1990s the belief was that, because asthma is an inflammatory disease, difficult-to-control asthma was best managed with increasing doses of inhaled corticosteroids. In contrast to this view, the addition of a long-acting $\beta_{2}$-agonist (LABA) to inhaled corticosteroid therapy has greater benefit on pulmonary function and asthma control than simply increasing the dose of inhaled corticosteroid [18]. A.P. Greening, from the School of Molecular and Clinical Medicine, University of Edinburgh, UK, recalled that, until 1994, the respiratory community believed that increasing the dose of inhaled corticosteroids was the best way to treat persistent asthma. In 1994, however, GREENING et al. [18] showed that the addition of a LABA to an inhaled corticosteroid provides superior improvements in lung function, as measured by peak expiratory flow, daytime and night-time symptoms, and use of rescue bronchodilator therapy, compared with increasing 
the dose of inhaled corticosteroid [18]. The results of this study [18] were soon confirmed by other clinical trials [19-21], and of particular significance was the finding that, at a given dose of inhaled corticosteroid, the addition of a LABA further reduces the exacerbation rate [20].

Mechanistically, there is some evidence to suggest synergy between inhaled corticosteroids and LABAs in clinical studies using both drugs in a single inhaler [22] and, in vitro, with salmeterol enhancing the effect of fluticasone propionate on T-cell apoptosis [23]. In addition, there is in vivo evidence that LABAs increase the nuclear translocation of the glucocorticoid receptor compared with inhaled steroid alone, a finding that supports the concept that there is a molecular basis for the complementary actions of LABAs and inhaled corticosteroids [24].

Combination therapy of inhaled corticosteroid plus LABA has revolutionised asthma treatment and it is now recommended practice for those patients who remain uncontrolled with lowdose inhaled corticosteroid therapy [6].

Results from the recently published Salmeterol Multicenter Asthma Research Trial (SMART) reinforce the principle that a LABA should not be taken without an inhaled corticosteroid [25]. This observational study showed a small but statistically significant increase in respiratory and asthma-related deaths in the total population receiving salmeterol. Post hoc analyses suggested that the number of respiratory related deaths or lifethreatening experiences in patients reporting no inhaled corticosteroid inhalation at baseline was greater in the salmeterol group than in the placebo group; however, in the group reporting inhaled corticosteroid use at baseline, there was no difference between salmeterol and placebo [25]. A.P. Greening commented that there were several study limitations and observed that the data appeared to conflict with those from a large population-based, case-controlled study of 532 patients who died from asthma and 532 control patients admitted to hospital for asthma, matched for period, age and geographical area. These data did not provide any evidence associating recent or long-term use of an inhaled LABA with an increased risk of asthma death [26].

Compared with inhaled corticosteroids, LABA monotherapy is not very effective [27]. However, the benefits of adding a LABA to inhaled corticosteroid therapy are well understood. It therefore seems sensible to recommend that LABAs should only be used in combination with inhaled corticosteroids, and preferably in a single device.

\section{STRATEGIES FOR CONTROL}

There is now a wealth of data confirming the benefits of combination therapy, yet debate remains on the best strategy for managing patients by this means. Two different strategies have been proposed, as follows: 1) regular maintenance dosing aiming for a high level of asthma control; and 2) a symptomdriven approach that allows the dose to vary according to the patient's symptoms by using inhaled corticosteroid plus LABA therapy for relief, as well as for maintenance therapy.

The GINA guidelines detail targets for asthma control using multiple criteria, including lung function, symptoms, night-time awakenings, rescue medication use, exacerbations, emergency visits and medication-related adverse events [6]. When these targets for control are compared with the results from the various studies using different treatment strategies, the current authors found that the study design and population can influence the outcomes. Support for the symptom-driven approach can be found in a study of patients receiving budesonide plus formoterol maintenance therapy plus one of three reliever medications: terbutaline, formoterol or budesonide/formoterol [28]. The study by RABE et al. [28] showed benefits from the use of inhaled corticosteroid plus LABA as maintenance and reliever therapy compared with the other two strategies. When compared with the other two arms, inhaled corticosteroid plus LABA as maintenance and reliever therapy showed a significantly increased time to first exacerbation and a reduced rate of severe exacerbations. In the same study [28], reliever therapy was used on average once a day, even in those patients receiving budesonide plus formoterol as maintenance and reliever therapy. Moreover, the patients receiving budesonide plus formoterol as both maintenance and reliever therapy still experienced nocturnal awakenings once a week. These outcomes do not represent control at the level defined by GINA [6].

The results of the study by RABE et al. [28] contrast with those of the EXacerbation Control EvaLuation (EXCEL) study [29], which looked at the effects of stable dosing with either salmeterol/fluticasone propionate $(50 / 250 \mu \mathrm{g}$, one inhalation b.i.d.) or formoterol/budesonide $(4.5 / 160 \mu \mathrm{g}$, two inhalations b.i.d.). In the EXCEL study [29], patients in both treatment arms experienced significant improvements in the number of rescuemedication-free days, with $\sim 82 \%$ of days being rescuemedication free. Stable dosing was associated with significantly improved asthma symptoms and lung function, and the exacerbation rate was significantly reduced over time [29].

At the symposium, A.P. Greening concluded that he believed regular maintenance dosing, aiming for the highest levels of control as stated by GINA, was preferable to a symptomdriven strategy. This second approach could potentially expose patients with milder disease to periods of worsened asthma because their preventative therapy is run, by definition, at the "bare minimum" levels.

\section{STABILITY OF CONTROL}

As previously discussed, asthma control is a more comprehensive measure of the disease that reflects the extrinsic modifiable variables of a patient's disease state, including triggers and treatment. Studies show that improved control of asthma is associated with reduced healthcare resource utilisation and reduced costs to healthcare providers and society compared with poorly controlled disease [30-32].

The Gaining Optimal Asthma controL (GOAL) study [33] was the first to show that the treatment aims set out by GINA are achievable. In the GOAL study [33], the dose of inhaled corticosteroid and LABA was stepped up before a period of stable dosing, and control was assessed using a composite measure derived from the GINA/National Institutes of Health guidelines [33]. A total of $59 \%$ of patients receiving fluticasone propionate and $71 \%$ receiving salmeterol/fluticasone propionate achieved "well controlled" asthma, and $28 \%$ of patients receiving fluticasone propionate and $41 \%$ receiving salmeterol/ 
fluticasone propionate achieved "totally controlled" asthma during the dose escalation phase of the study (phase I).

The level of control, however, is not the only factor to consider, for both the physician and the patient, the variability of control can be as important as the level, and would be expected to have an impact on healthcare resource use and the patient's quality of life. According to E.D. Bateman (Division of Pulmonology, University of Cape Town, South Africa), for many patients with asthma, life is haunted by fear as a result of variability in the control of their disease. For optimal quality of life, it is not enough to simply achieve control; control must be maintained.

In the GOAL study [33], overall Asthma Quality of Life Questionnaire (AQLQ) scores gained or approached maximal levels in patients who achieved totally controlled and well controlled asthma, suggesting that, in these patients, asthma had a minimal impact on quality of life (E.D. Bateman, personal communication). Achieving totally controlled and well controlled asthma in the dose escalation period (phase I) was associated with mean overall AQLQ scores of 6.4 and 6.1, respectively, in the stable dosing period (phase II). In contrast, the mean overall AQLQ score for those not achieving at least well controlled asthma was 5.3 (all strata, both treatments combined; E.D. Bateman, personal communication).

During the symposium at the European Respiratory Society Annual Congress in 2006 presently being discussed, the question of what the differences are between the two levels of control that are perceptible to patients was raised. According to E.D. Bateman, greater stability of control might translate into perceptible differences and increased quality of life.

In the GOAL study [33], patients who achieved totally controlled asthma demonstrated the greatest stability of control and maintained stable control for longer periods than those who were only well controlled or not well controlled (E.D. Bateman, personal communication). This analysis used a Markov model with four disease control states: totally controlled, well controlled, not well controlled without exacerbation and not well controlled with exacerbation. Such an approach to modelling control is supported by previous work [34], in which control was defined according to three health states: optimal, suboptimal and unacceptable control (states 1, 2 and 3, respectively). Transition probabilities between these three control states were assessed. In the study by COMBESCURE et al. [34], it was found that patients with mildto-moderate asthma in suboptimal or unacceptable control had a high probability of transition directly to optimal control, whereas patients with severe asthma had a greater tendency to remain in unacceptable control. These results suggest that most of the changes in control status occur during the first 3 months of treatment and this finding may be used to argue against frequent changes in treatment during this initial period. In addition, the results provide clues as to when the final achievable control level can be attained in most patients and when step-down of treatment might be considered.

The data showing benefits of combination treatment in achieving and sustaining control are reinforced by the results of a 3-yr study in which a large population of patients were treated with salmeterol monotherapy, fluticasone propionate monotherapy or salmeterol/fluticasone propionate [35, 36]. Provided that patients had no more than one exacerbation, they continued on the assigned therapy throughout the 1-yr, doubleblind treatment period. Then, during the 2-yr, open-label, follow-up period, physicians were given the option to switch therapy, with the aim being comprehensive disease control. During the double-blind period, control was achieved more frequently in the group treated with salmeterol/fluticasone propionate than in the other two arms [36]. Sustained control was associated with improvements in airway hyperresponsiveness, lung function, rescue-medication use and symptom scores. These benefits were sustained during the open-label period, during which time most patients required, and benefited from, combination treatment [35]. These results demonstrate that sustained treatment is necessary to achieve and maintain control, and that the addition of a LABA enables greater proportions of patients to achieve this aim.

GINA recommends that once control has been achieved and maintained, treatment should be reviewed and dose reduction attempted, while ensuring that control is not lost [6]. The first study that specifically looked at stepping down salmeterol/ fluticasone propionate treatment while aiming to maintain control showed that, following achievement of well controlled asthma on salmeterol/fluticasone propionate $250 / 50 \mu \mathrm{g}$ b.i.d., stepping down to $100 / 50 \mu$ g b.i.d. enabled the maintenance of control for 12 weeks in the majority of patients. Compared with discontinuing the LABA component by switching to inhaled corticosteroid alone, stepping down to combination treatment with a lower inhaled corticosteroid dose resulted in improved lung function and a greater proportion of patients remaining well controlled [37]. Nevertheless, further research is required to determine the optimal control level, or interval after attaining control, at which the dose should be stepped down. Accordingly, the question of stepping down treatment was a topic that attracted much interest throughout the symposium. E.D. Bateman stated that strict control should be the aim of therapy and that there are few scenarios in which treatment should not be stepped down. Such scenarios might include, for example, patients with severe life-threatening asthma with many previous exacerbations. E.D. Bateman affirmed that the rationale of the GOAL study [33] was not to justify high-dose inhaled corticosteroid, but to investigate whether guideline-defined control was achievable. In all cases, the cost and safety of therapy must be weighed against the clear benefits of achieving comprehensive control. He pointed out that there are concerns about the use of high-dose inhaled corticosteroid and that combination therapy allows control to be achieved using lower doses of inhaled corticosteroids. The GOAL study [33], however, was not designed to investigate approaches to step-down therapy.

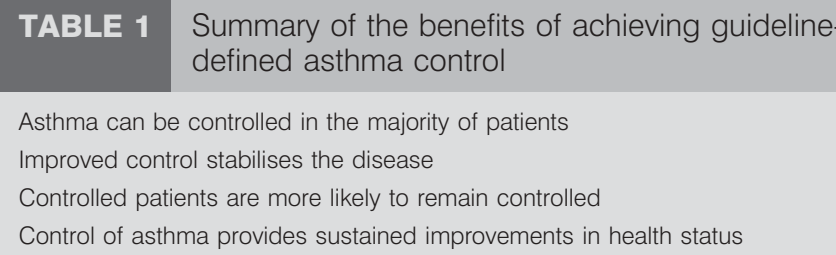




\section{TABLE 2 The Asthma Control Test (ACT $\left.{ }^{\mathrm{TM}}\right)$}

\section{Questions}

1. In the past 4 weeks how much of the time did your asthma keep you from getting as much done at work, school or at home?

All the time

Most of the time

Some of the time

A little of the time

None of the time

2. During the past 4 weeks, how often have you had shortness of breath?

More than once a day

Once a day

3-6 times a week

Once or twice a week

Not at all

3. During the past 4 weeks, how often did your asthma symptoms (wheezing, coughing, shortness of breath, chest tightness or pain) wake you up at night or earlier than usual in the morning?

$\geqslant 4$ nights a week

2-3 nights a week

Once a week

Once or twice

Not at all

4. During the past 4 weeks, how often have you used your rescue inhaler or nebuliser medication, such as albuterol?

$\geqslant 3$ times a day

1-2 times a day

2-3 times a week

Once a week or less

Not at all

5. How would you rate your asthma control during the past 4 weeks?

Not controlled at all

Poorly controlled

Somewhat controlled

Well controlled

Completely controlled

The score of 1 to 5 is based on 1 being the worst controlled and 5 being the best controlled. The ACT ${ }^{\mathrm{TM}}$ is copyright and trademark of Quality Metric Inc., 2002 .

E.D. Bateman concluded that improved control stabilises asthma, leading to fewer "bad" days and fewer exacerbations. As such, controlled asthma becomes a stable disease (table 1). This is in contrast with uncontrolled asthma, which remains a variable disease, with the accompanying reduced quality of life associated with instability.

\section{MEASURING ASTHMA CONTROL IN THE CLINIC}

Given that aiming for guideline-defined control of asthma results in better outcomes for patients, J.C. Virchow highlighted the need for a way to monitor asthma control in the real-life clinical practice setting. Historically, there have been difficulties with this approach because there has been no clear definition as to what precisely constitutes "control". Such a lack of consensus has meant that, despite the availability of efficacious therapies and international treatment guidelines, outcomes have remained poor, as shown by a study by GALLEFOSS [38].

Large, international surveys have shown that patients habitually under-report their symptoms and overestimate their level of control, resulting in the undertreatment of asthma [39]. This could be, in part, due to patients adjusting their lifestyle to cope with symptoms. The issue is further complicated by the fact that physicians often underestimate their patients' symptoms. The UK Asthma in Real life (AIR) study was a questionnaire survey of 536 children and 960 adults with asthma [40]. In the AIR study [40], a total of $79 \%$ of patients considered their asthma to be either well controlled or totally controlled, despite the fact that approximately one-third of these patients reported using a rescue $\beta_{2}$-agonist on the previous day. Approximately one-third of patients reported symptoms at least once a week and, in general, patients described a "bad asthma day" as one in which they were unable to carry out normal activities.

J.C. Virchow discussed the various options for assessing asthma control, including symptoms, lung function, healthcare resource use, airway hyperresponsiveness, biomarkers of inflammation, health status and asthma questionnaires. Measures such as airway hyperresponsiveness, biomarkers and health status are not often used in practice; what is needed 


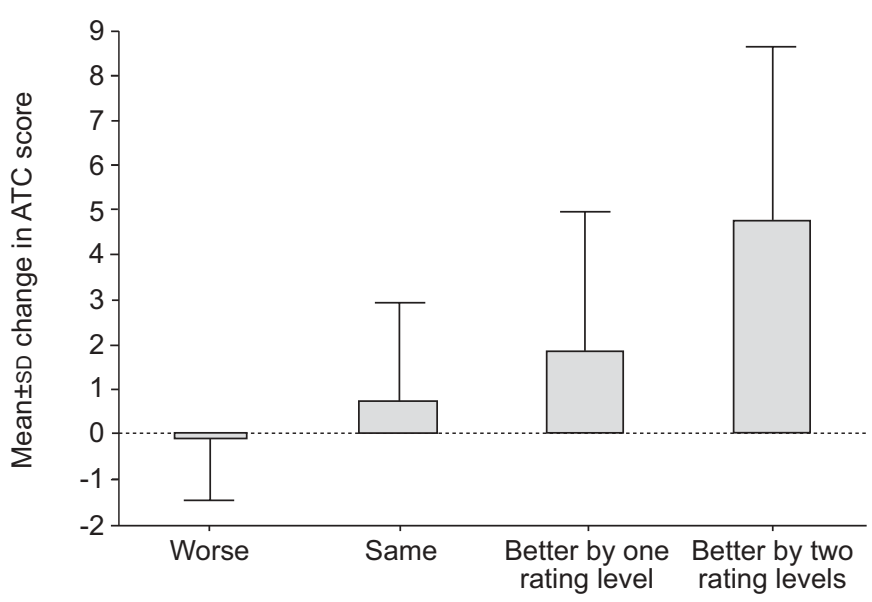

Specialist global rating of change

FIGURE 4. The Asthma Control Test $\left(A C T^{\top M}\right)$ detects clinically meaningful changes in asthma control. The ACT was administered to 248 patients during two visits to asthma specialists. The specialists were blinded to ACT scores. They rated asthma control after spirometry. Changes in specialist ratings were scored by subtracting follow-up ratings from baseline ratings. Four levels of change were derived, as follows: -1 : one or more levels of worsening $(n=44)$; 0 : same $(n=85)$; +1 : one level of improvement $(n=80)$; +2 : two levels of improvement $(n=37)$. ANOVA was used to compare changes in mean ACT scores across four levels of patients differing in change in specialist ratings. Significant differences in mean change scores on the ACT were observed across four categories of change in specialist rating $(F=22.5, p<0.001)$. Reproduced and modified from [43] with permission of the publisher.

is a tool that can be used in clinical practice and that takes into account measures that are meaningful to the patient, such as limitations on activities, exacerbations, symptoms and the use of rescue medication. In addition, such a tool should be applicable to a range of patients and be sensitive to changes in the patient's disease. Ideally, patient involvement should be a key part of any tool because this could aid treatment adherence.

\section{Asthma Control Test: a validated tool for assessing asthma control}

The Asthma Control Test $\left(\mathrm{ACT}^{\mathrm{TM}}\right)$ was designed to meet the need for a patient-based tool for identifying poorly controlled asthma (table 2). Of all available asthma control tools, the ACT has been subjected to the greatest number of validation tests. A clinical validation study tested the reliability and validity of the components and criteria, and showed the five items most predictive of uncontrolled asthma to be as follows: 1) shortness of breath; 2) patient rating of asthma control; 3) use of rescue medication; 4) asthma preventing the patient getting as much done at work/home; and 5) waking with asthma symptoms at night [41]. A longitudinal reliability and validation study showed that the ACT performed well compared with specialists' ratings of asthma control and the Asthma Control Questionnaire. In particular, changes in ACT scores correlated with changes in specialists' ratings (fig. 4) [42].

A study in a general population of asthmatics found that, if spirometry is not available, the ACT alone is a good screening tool for identifying uncontrolled patients; however, using both the ACT and spirometry increases sensitivity [43]. The ACT has also been shown to be useful in assessing the cost of uncontrolled asthma [44].

J.C. Virchow presented unpublished data from a German internet-based survey [45] showing that the majority of patients completing the test were suboptimally controlled. Although there is a possibility for a selection bias with internet-based surveys, these results seem disappointing given the availability of effective treatment.

In conclusion, J.C. Virchow noted that the ACT is a useful screening tool for uncontrolled asthma in both daily clinical practice and at home. In certain clinical situations, the addition of data on exhaled nitric oxide, airway hyperresponsiveness and sputum eosinophilia to pulmonary function and symptoms might provide complementary information on control. It is unclear, however, if such measurements would aid in the assessment of asthma in large populations: evidence for their use in assessment comes from highly selected studies enrolling small numbers of patients. Furthermore, it is possible that inclusion of such parameters would make assessment and management more complicated and expensive. Therefore, evaluation and validation of these measurements in largescale studies is necessary. Further studies on the long-term use of the ACT as a monitoring tool are also required.

\section{SUMMARY AND CONCLUSIONS}

Control of asthma is the ultimate goal of asthma therapy. Treating the underlying airway inflammation associated with asthma is the most effective method for achieving control. When considering treatment strategies employing inhaled corticosteroid and long-acting $\beta_{2}$-agonist, a regular dosing strategy may be preferable to a symptom-driven treatment strategy, because a regular dosing strategy containing a dose of inhaled corticosteroid sufficient to meet guideline objectives of asthma control may avoid the patient modifying lifestyle to avoid symptoms and may be more efficacious in protecting patients from periods of uncontrolled asthma. Once control is achieved it should be maintained to give the greatest benefits in terms of health-related quality of life. As part of achieving these aims, the Asthma Control Test is an important tool for assessing asthma control in clinical practice.

\section{ACKNOWLEDGEMENTS}

A.P. Greening has received an investigator led grant from GlaxsoSmithKline, and has also received speaker's and consultancy fees. Members of A.P. Greening's Unit have received travel support to attend American Thoracic Society and European Respiratory Society meetings. D. Stempel has received fees for speaking and consultancy from GlaxoSmithKline over the past 5 yrs. Since October 2006, D. Stempel has been an employee of GlaxoSmithKline. E.D. Bateman has received honoraria for serving on advisory boards for Almirall, AstraZeneca, Altana, Boehringer Ingelheim, GlaxoSmithKline, Hoffmann le Roche, Kyowa Hakko, Merck, Nycomed, Pfizer and Sanofi-Aventis, and for lectures organised by Altana, AstraZeneca, Boehringer Ingelheim, GlaxoSmithKline, Nycomed and Pfizer. J.C. Virchow has received research funds, and speaking and consultancy fees from GlaxoSmithKline. 
This manuscript was written by the authors reflecting the contents of a symposium, at the European Respiratory Society Annual Congress, held in Munich in September 2006.

\section{REFERENCES}

1 Campbell MJ, Cogman GR, Holgate ST, Johnston SL. Age specific trends in asthma mortality in England and Wales, 1983-95: results of an observational study. BMJ 1997; 314: 1439-1441.

2 Soler M, Chatenoud L, Negri E, La Vecchia C. Trends in asthma mortality in Italy and Spain, 1980-1996. Eur J Epidemiol 2001; 17: 545-549.

3 American Lung Association Epidemiology and Statistics Unit Research and Program Services 2005, Trends in asthma morbidity and mortality. New York, American Lung Association, 2006; pp. 1-40.

4 Getahun D, Demissie K, Rhoads GG. Recent trends in asthma hospitalization and mortality in the United States. J Asthma 2005; 42: 373-378.

5 Masoli M, Fabian D, Holt S, Beasley R. The global burden of asthma: executive summary of the GINA Dissemination Committee report. Allergy 2004; 59: 469-478.

6 Global Initiative for Asthma (GINA). Global Strategy for Asthma Management and Prevention, 2006. www.ginasthma. org Date last updated: December 2007. Date last accessed: February 20, 2008.

7 Fuhlbrigge AL, Adams RJ, Guilbert TW, et al. The burden of asthma in the United States: level and distribution are dependent on interpretation of the national asthma education and prevention program guidelines. Am J Respir Crit Care Med 2002; 166: 1044-1049.

8 Bateman ED. Measuring asthma control. Curr Opin Allergy Clin Immunol 2001; 1: 211-216.

9 Barnes NC, Williams AE. Unscheduled healthcare resource use among asthma patients receiving low-dose inhaled corticosteroids maintenance treatment. Int J Clin Pract 2005; 59: 1017-1024.

10 Chapman KR. Impact of "mild" asthma on health outcomes: findings of a systematic search of the literature. Respir Med 2005; 99: 1350-1362.

11 Zeiger RS, Bird SR, Kaplan MS, et al. Short-term and longterm asthma control in patients with mild persistent asthma receiving montelukast or fluticasone: a randomized controlled trial. Am J Med 2005; 118: 649-657.

12 Robertson CF, Rubinfeld AR, Bowes G. Pediatric asthma deaths in Victoria: the mild are at risk. Pediatr Pulmonol 1992; 13: 95-100.

13 van den Toorn LM, Overbeek SE, de Jongste JC, Leman K, Hoogsteden HC, Prins JB. Airway inflammation is present during clinical remission of atopic asthma. Am J Respir Crit Care Med 2001; 164: 2107-2113.

14 Rennard SI. Repair mechanisms in asthma. J Allergy Clin Immunol 1996; 98: Suppl. 6, S278-S286.

15 Bousquet J, Jeffery PK, Busse WW, Johnson M, Vignola AM. Asthma from bronchoconstriction to airways inflammation and remodeling. Am J Respir Crit Care Med 2000; 161: 1720-1745.

16 van den Toorn LM, Prins JB, de Jongste JC, et al. Benefit from anti-inflammatory treatment during clinical remission of atopic asthma. Respir Med 2005; 99: 779-787.
17 Kharitonov S, Alving K, Barnes PJ. Exhaled and nasal nitric oxide measurements: recommendations. The European Respiratory Society Task Force. Eur Respir J 1997; 10: 1683-1693.

18 Greening AP, Ind PW, Northfield M, Shaw G. Added salmeterol versus higher-dose corticosteroid in asthma patients with symptoms on existing inhaled corticosteroid. Lancet 1994; 344: 219-224.

19 Woolcock A, Lundback B, Ringdal N, Jacques LA. Comparison of addition of salmeterol to inhaled steroids with doubling of the dose of inhaled steroids. Am J Respir Crit Care Med 1996; 153: 1481-1418.

20 Pauwels RA, Lofdahl CG, Postma DS, et al. Effect of inhaled formoterol and budesonide on exacerbations of asthma. Formoterol and Corticosteroids Establishing Therapy (FACET). N Engl J Med 1997; 337: 1405-1411.

21 Wilding P, Clark M, Thompson CJ, et al. Effect of long-term treatment with salmeterol on asthma control: a double blind, randomised crossover study. BMJ 1997; 314: 1441-1446.

22 Nelson HS, Chapman KR, Pyke SD, Johnson M, Pritchard JN Enhanced synergy between fluticasone propionate and salmeterol inhaled from a single inhaler versus separate inhalers. J Allergy Clin Immunol 2003; 112: 29-36.

23 Pace E, Gagliardo R, Melis M, et al. Synergistic effects of fluticasone propionate and salmeterol on in vitro T-cell activation and apoptosis in asthma. J Allergy Clin Immunol 2004; 114: 1216-1223.

24 Usmani OS, Ito K, Maneechotesuwan $\mathrm{K}$, et al. Glucocorticoid receptor nuclear translocation in airway cells after inhaled combination therapy. Am J Respir Crit Care Med 2005; 172: 704-712.

25 Nelson HS, Weiss ST, Bleecker ER, Yancey SW, Dorinsky PM. The Salmeterol Multicenter Asthma Research Trial: a comparison of usual pharmacotherapy for asthma or usual pharmacotherapy plus salmeterol. Chest 2006; 129: 15-26.

26 Anderson HR, Ayres JG, Sturdy PM, et al. Bronchodilator treatment and deaths from asthma: case-control study. BMJ 2005; 330: 117.

27 Kavuru M, Melamed J, Gross G, et al. Salmeterol and fluticasone propionate combined in a new powder inhalation device for the treatment of asthma: a randomized, double-blind, placebo-controlled trial. I Allergy Clin Immunol 2000; 105: 1108-1116.

28 Rabe KF, Atienza T, Magyar P, Larsson P, Jorup C, Lalloo UG. Effect of budesonide in combination with formoterol for reliever therapy in asthma exacerbations: a randomised controlled, double-blind study. Lancet 2006; 368: 744-753.

29 Dahl R, Chuchalin A, Gor D, Yoxall S, Sharma R. EXCEL: a randomised trial comparing salmeterol/fluticasone propionate and formoterol/budesonide combinations in adults with persistent asthma. Respir Med 2006; 100: 1152-1162

30 Vollmer WM, Markson LE, O'Connor E, Frazier EA, Berger M, Buist AS. Association of asthma control with health care utilization: a prospective evaluation. Am J Respir Crit Care Med 2002; 165: 195-199.

31 Sullivan SD, Rasouliyan L, Russo PA, Kamath T, Chipps BE. Extent, patterns and burden of uncontrolled disease in severe or difficult-to-treat asthma. Allergy 2007; 62: 126-133. 
32 Peters D, Chen C, Markson LE, Allen-Ramey FC, Vollmer WM. Using an asthma control questionnaire and administrative data to predict health-care utilization. Chest 2006; 129: 918-924.

33 Bateman ED, Boushey HA, Bousquet J, et al. Can guidelinedefined asthma control be achieved? The Gaining Optimal Asthma controL study. Am J Respir Crit Care Med 2004; 170: 836-844.

34 Combescure C, Chanez P, Saint-Pierre P, Daures JP, Proudhon H, Godard P. Assessment of variations in control of asthma over time. Eur Respir J 2003; 22: 298-304.

35 Lundback B, Ronmark E, Lindberg A, et al. Asthma control, if achieved and maintained, eliminates airway hyperreactivity: a 3 year study. Eur Respir J 2006; 28: Suppl. 50, 218 s.

36 Lundback B, Ronmark E, Lindberg A, et al. Control of mild to moderate asthma over 1-year with the combination of salmeterol and fluticasone propionate. Respir Med 2006; 100: 2-10.

37 Bateman ED, Jacques L, Goldfrad C, Atienza T, Mihaescu T, Duggan M. Asthma control can be maintained when fluticasone propionate/salmeterol in a single inhaler is stepped down. J Allergy Clin Immunol 2006; 117: 563-570.

38 Gallefoss F. Implementing guidelines to achieve asthma control in clinical practice. Eur Respir Rev 2004; 13: 113-115.
39 Rabe KF, Adachi M, Lai CK, et al. Worldwide severity and control of asthma in children and adults: the global asthma insights and reality surveys. J Allergy Clin Immunol 2004; 114: 40-47.

40 Price D, Ryan D, Pearce N, Bride F. The AIR study: asthma in real life. Asthma J 2006; 4: 74-78.

41 Nathan RA, Li JT, Finn A, et al. A dose-ranging study of fluticasone propionate administered once daily via multidose powder inhaler to patients with moderate asthma. Chest 2000; 118: 296-302.

42 Schatz M, Sorkness CA, Li JT, et al. Asthma Control Test: reliability, validity, and responsiveness in patients not previously followed by asthma specialists. J Allergy Clin Immunol 2006; 117: 549-556.

43 Lenoir M, Williamson A, Stanford RH, Stempel DA. Assessment of asthma control in a general population of asthmatics. Curr Med Res Opin 2006; 22: 17-22.

44 Vervloet D, Williams AE, Lloyd A, Clark TJH. Costs of managing asthma as defined by a derived Asthma Control Test $^{\mathrm{TM}}$ score in seven European Countries. Eur Respir Rev 2006; 15: 17-23.

45 Asthma Control Test. www.asthmacontrol.com/ Date last accessed: March 2008. 